\title{
Effects of Synchronization During Nasal Ventilation in Clinically Stable Preterm Infants
}

\author{
HUNG-YANG CHANG, NELSON CLAURE, CARMEN D'UGARD, JUAN TORRES, PATRICK NWAJEI, \\ AND EDUARDO BANCALARI
}

\begin{abstract}
Department of Pediatrics [H.-Y.C., N.C., C.D., J.T., P.N., E.B.], Jackson Memorial Hospital, University of Miami, Miami, Florida 33101; Department of Pediatrics [H.-Y.C.], Hsinchu Mackay Memorial Hospital, Hsinchu City, Mackay Medicine, Nursing and Management College, Taipei 30071, Taiwan
\end{abstract}

\begin{abstract}
Nasal ventilation is increasingly used to reduce invasive ventilation in preterm infants. The effects of nasal ventilation and the advantages of synchronized nasal ventilation have not been fully evaluated. The objective was to compare the short-term effects of nasal intermittent mandatory ventilation (NIMV) and synchronized NIMV (S-NIMV) with nasal continuous positive airway pressure (NCPAP) on ventilation, gas exchange, and infant-ventilator interaction. Sixteen clinically stable preterm infants requiring NCPAP (GA, $27.6 \pm 2.3 \mathrm{wk}$; birthweight $(\mathrm{BW}), 993 \pm 248 \mathrm{~g}$; and age, $15 \pm 14 \mathrm{~d}$ ) were exposed to NCPAP, NIMV at 20/min, NIMV at 40/min, S-NIMV at 20/min, and S-NIMV at 40/min for $1 \mathrm{~h}$ each (Infant-Star ventilator), in random order. Tidal volume, minute ventilation, and gas exchange did not differ significantly between NCPAP, NIMV, and S-NIMV. Inspiratory effort decreased during S-NIMV compared with NCPAP and NIMV, whereas inspiratory effort during NIMV did not differ from NCPAP. Active expiratory effort and expiratory duration increased during NIMV. Chest wall distortion, apnea and hypoxemia spells, abdominal girth, and comfort did not differ. In conclusion, there were no short-term benefits on ventilation and gas exchange of nasal ventilation compared with NCPAP in clinically stable preterm infants. However, synchronized nasal ventilation reduced breathing effort and resulted in better infant-ventilator interaction than nonsynchronized nasal ventilation. (Pediatr Res 69: 84-89, 2011)
\end{abstract}

$\mathrm{D}$ espite advances in neonatal respiratory care, bronchopulmonary dysplasia remains a frequent complication in preterm infants, and invasive mechanical ventilation is a major risk factor $(1,2)$. This led to the use of noninvasive respiratory support to reduce complications associated with invasive mechanical ventilation in preterm infants. Nasal continuous positive airway pressure (NCPAP) is the most common form of noninvasive respiratory support used in these infants. However, studies have shown important failure rates of NCPAP in preventing invasive ventilation or after extubation in the smaller infants (3-5). Efforts to reduce failure prompted the use of nasal ventilation that has been found to be more effective than NCPAP in preventing extubation failure (6-9)

Received March 3, 2010; accepted September 9, 2010.

Correspondence: Nelson Claure, Ph.D., Department of Pediatrics, Division of Neonatology, University of Miami Miller School of Medicine, PO Box 016960 R-131, Miami, FL 33101; e-mail: nclaure@miami.edu

Supported by University of Miami Project: New Born and the Bank of America Charitable Foundation. and as a primary mode of support in respiratory distress syndrome (RDS) (10-12).

The most commonly reported modes of nasal ventilation are nasal intermittent mandatory ventilation (NIMV) and synchronized NIMV (S-NIMV). However, the effects of nasal ventilation on respiratory function and the possible advantages of synchronization during nasal ventilation have not been fully evaluated.

The objective of this study was to evaluate the physiologic effects of synchronization during nasal ventilation in stable preterm infants. It was hypothesized that S-NIMV will improve tidal volume $\left(\mathrm{V}_{\mathrm{T}}\right)$ and minute ventilation $\left(\mathrm{V}_{\mathrm{E}}\right)$ when compared with NCPAP and nonsynchronized NIMV. Second, it will improve gas exchange, reduce patient effort and chest wall distortion, and decrease frequency of apnea and hypoxemia spells.

\section{METHODS}

Patient population. Clinically stable preterm infants born at $<32 \mathrm{wk}$ of gestation and weighing under $1500 \mathrm{~g}$ at birth, who required NCPAP were eligible for the study. Infants with major congenital anomalies, requiring sedation, or with ongoing sepsis or meningitis were excluded. The study was conducted at the University of Miami/Jackson Memorial Hospital NICU. The study was approved by Institutional Review Boards of the University of Miami and Jackson Memorial Hospital. All infants were recruited and studied after written informed parental consent was obtained.

In the absence of preliminary data on the primary outcome measure of $\mathrm{V}_{\mathrm{T}}$ between NIMV and S-NIMV, data from Hummler et al. (13) comparing IMV and SIMV in intubated infants was used to estimate the sample size. Enrollment of at least 16 infants was estimated to detect a $24 \%$ within-subject difference in $\mathrm{V}_{\mathrm{T}}$ between S-NIMV and NIMV with a 0.9 power and 0.05 alpha.

Study protocol. Infants were studied in their incubators, while they were left undisturbed and after standard nursing procedures were completed. The infants were in supine position throughout the study. During the study, infants underwent a sequence of five 1-h study periods: NCPAP, NIMV at 20/min, NIMV at $40 / \mathrm{min}$, S-NIMV at $20 / \mathrm{min}$, and S-NIMV at $40 / \mathrm{min}$. The sequence

\footnotetext{
Abbreviations: $\mathbf{F i O}_{2}$, fraction of inspired oxygen; NCPAP, nasal continuous positive airway pressure; NIMV, nasal intermittent mandatory ventilation; $\mathbf{P}_{\mathbf{A W}}$, airway pressure; PEEP, positive end-expiratory pressure; $\mathbf{P}_{\mathbf{E S}}$, esophageal pressure; $\mathbf{P}_{\mathbf{E S}}$ inspiratory area, area under the esophageal pressure curve in inspiration; $\mathbf{P}_{\mathbf{E S} \text { minute inspiratory area }}$, per minute area under the esophageal

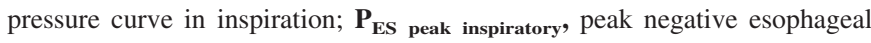
pressure in inspiration; $\mathbf{P}_{\text {ES peak expiratory }}$, peak positive esophageal pressure in exhalation; PIP, peak inspiratory pressure; RIP, respiratory inductance plethysmography; RR, respiratory rate; S-NIMV, synchronized nasal intermittent mandatory ventilation; $\mathbf{S p O}_{2}$, arterial oxygen saturation measured by pulse oximetry; TCD ratio, total compartment displacement ratio; $\mathbf{T} \mathbf{P C O} \mathbf{P C}_{2}$, transcutaneous $\mathrm{CO}_{2}$ tension; $\mathbf{V}_{\mathbf{T}}$, tidal volume; $\mathbf{V}_{\mathbf{E}}$, minute ventilation
} 
of these five periods was determined at random for each infant. There were 10-min intervals for stabilization between study periods. Investigators were not blinded to the treatment mode.

NIMV and S-NIMV were provided through the same short binasal prongs used for NCPAP (INCA prongs; Ackrad Labs, Copper Surgical, Trumbull, CT). All infants had a NCPAP seal (Cannulaide; Beevers Manufacturing, McMinnville, OR). There were no steps taken to maintain the infant's mouth closed (e.g. use of chin straps) or restrain them. The position of the nasal prongs was continuously monitored for dislodgement. NCPAP, NIMV, and S-NIMV were provided by a time-cycled, pressure-limited neonatal ventilator (Infant Star 950; Infrasonics, Inc., San Diego, CA). Synchronization was achieved by a Graseby capsule taped on the abdominal wall. Position of the capsule and trigger sensitivity were adjusted in each patient to achieve minimal trigger delay without autotriggering by observing the timing of esophageal pressure $\left(\mathrm{P}_{\mathrm{ES}}\right)$ deflection during spontaneous inspiration, capsule pressure, and the ventilator cycle. Positive end-expiratory pressure (PEEP) was set at the same level as NCPAP before the study, peak inspiratory pressure (PIP) was set at $10 \mathrm{~cm} \mathrm{H}_{2} \mathrm{O}$ above the level of PEEP, and inspiratory time was set at $0.3 \mathrm{~s}$. The ventilator pressure was measured at the connector between the circuit and the nasal prongs. If required, the ventilator's peak pressure or bias flow was adjusted to reach the set PIP. The fraction of inspired oxygen $\left(\mathrm{FiO}_{2}\right)$ was adjusted to maintain arterial oxygen saturation $\left(\mathrm{SpO}_{2}\right)$ between 88 and $93 \%$.

Measurements. Respiratory activity and chest wall instability were measured by respiratory inductance plethysmography (RIP) using two soft elastic bands placed around the abdomen and chest (Respitrace Plus; Sensormedics Corporation, Yorba Linda, CA). These bands were secured with tape. The relative contribution of the chest wall and abdominal signals was determined by the qualitative diagnostic calibration method. The RIP chest wall and abdominal signals were added to yield a third signal, denoted the sum signal that was used to obtain of $\mathrm{V}_{\mathrm{T}}, \mathrm{V}_{\mathrm{E}}$, and respiratory rate (RR).

$\mathrm{P}_{\mathrm{ES}}$ was measured with a size 5-Fr water-filled feeding orogastric catheter with the tip placed in the lower esophagus. First, the insertion length to the stomach and lower esophagus was estimated, and the tip of the catheter was inserted into the stomach. This was confirmed by the positive deflection in pressure during inspiration in synchrony with the outward movement of the RIP band on the abdomen. Subsequently, the catheter was slowly withdrawn until the pressure deflection during inspiration became negative. In this position, the insertion length was noted and the catheter secured. If the inspiratory deflection in pressure was small, a brief airway occlusion was done to confirm transmission of pressure. Patency was maintained during the study by the flushing the catheter. An orogastric feeding catheter was in place throughout the study for feeding and gastric gas decompression. Airway pressure $\left(\mathrm{P}_{\mathrm{AW}}\right)$ was measured at the connection between the ventilator circuit and the nasal adaptor. Both $\mathrm{P}_{\mathrm{ES}}$ and $\mathrm{P}_{\mathrm{AW}}$ were measured with pressure transducers (Sorenson Transpac 42586-1; Abbot critical care systems, North Chicago, IL) connected to medical grade transducer couplers (Gould Electronics, Inc., Valley View, $\mathrm{OH}$ ) and calibrated by water manometry.

$\mathrm{SpO}_{2}$ was continuously measured by pulse oximetry (Radical; Masimo, Corp., Irvine, CA). Transcutaneous $\mathrm{CO}_{2}$ tension $\left(\mathrm{TcPCO}_{2}\right)$ was measured using a transcutaneous carbon dioxide monitor (Microgas 7650; Sensormedics Corporation, Yorba Linda, CA). $\mathrm{FiO}_{2}$ was measured with an oxygen analyzer (O2000; Maxtec, Salt Lake City, UT). All signals were digitized at 100 samples per second and recorded on a personal computer (AT-CODAS; Dataq Instruments, Akron, $\mathrm{OH}$ ).

Patient comfort was assessed at the beginning of each 1-h period and every 20 min by two unmasked researchers using a score system simplified from a validated scale (14). This score included sleep state (0, sleep and 1, awake), calmness/agitation ( 0 , calm; 1 , mildly agitated; and 2 , very agitated), crying ( 0 , no and 1 , crying), movement $(0$, no; 1 , slight; and 2 , vigorous $)$, and facial expression ( 0 , normal and 1 , contorted/grimacing). Abdominal circumference was measured before and at the end of each period.

Data analysis. The mean $\mathrm{V}_{\mathrm{T}}$ from all spontaneous and ventilator cycles (S-NIMV or NIMV) during each mode of support was obtained from the RIP sum signal during each 1 -h recording period using computerized analysis without operator intervention. $\mathrm{V}_{\mathrm{E}}$ was derived from the mean $\mathrm{V}_{\mathrm{T}}$ and $\mathrm{RR}$ of every minute for each mode of support. $V_{T}$ is reported in arbitrary units $(A U), V_{E}$ in AU per minute, and RR in breaths per minute. Apnea episodes, defined as respiratory pauses lasting $>20 \mathrm{~s}$ in the RIP sum signal, were counted for each mode of support. Computerized analysis of the entire 1-h periods was used to determine mean $\mathrm{TcPCO}_{2}, \mathrm{SpO}_{2}$, and $\mathrm{FiO}_{2}$ as well as episodes with $\mathrm{SpO}_{2}<85 \%$.

Data on parameters of breathing effort and chest wall distortion were calculated from all consecutive artifact-free breaths during $1 \mathrm{~min}$ and every 15 min throughout each 1 -h period. These included nonassisted spontaneous breaths, ventilator cycles in synchrony with spontaneous inspiration, nonsynchronous ventilator cycles, and ventilator cycles during periods of apnea. Breaths were considered unsuitable for analysis if the
$\mathrm{P}_{\mathrm{ES}}$ or RIP signals drifted or if there was movement artifact. Per-breath spontaneous inspiratory effort was determined by peak negative $\mathrm{P}_{\mathrm{ES}}$ during inspiration $\left(\mathrm{P}_{\mathrm{ES}}\right.$ peak inspiratory $)$ and the area under the $\mathrm{P}_{\mathrm{ES}}$ curve $\left(\mathrm{P}_{\mathrm{ES}}\right.$ inspiratory area). Minute effort ( $\left.\mathrm{P}_{\mathrm{ES} \text { minute inspiratory area }}\right)$ was calculated as the product of $\mathrm{P}_{\mathrm{ES}}$ inspiratory area and RR. Active spontaneous expiratory effort was determined by peak positive $\mathrm{P}_{\mathrm{ES}}$ during exhalation $\left(\mathrm{P}_{\mathrm{ES} \text { peak expiratory }}\right)$.

To analyze the per-breath effects of timing of ventilator cycle with respect to spontaneous breath, $\mathrm{V}_{\mathrm{T}}, \mathrm{P}_{\mathrm{ES} \text { inspiratory area, }} \mathrm{P}_{\mathrm{ES} \text { peak expiratory, and expiratory }}$ duration were obtained from NIMV cycles delivered during the first half of inspiration, second half of inspiration, first half of exhalation, or second half of exhalation. These parameters were compared with those obtained from S-NIMV cycles and from nonassisted spontaneous breaths during NCPAP, or between NIMV or S-NIMV cycles.

Thoracoabdominal motion was analyzed by determining the phase delay between abdominal and chest wall expansion expressed in degrees as a fraction of the full respiratory cycle represented by $360^{\circ}$. The ratio of the displacement of the ribcage and abdomen compartments to the net volume displacement was denoted as the total compartment displacement ratio (TCD ratio). TCD ratio was calculated as the sum of the absolute values of the abdominal and thoracic signal's area under the curve divided by their algebraic sum (sign included). In cases where no chest wall distortion is present, the TCD ratio is equal to 1 . Increasing values $>1$ in TCD ratio reflected greater chest wall distortion with more displacement than volume achieved.

Within-subject comparisons of the five study periods was done using repeated measures ANOVA or repeated measures ANOVA on ranks when the data were not normally distributed. Post hoc analysis to determine between periods differences was done using the Student-Newman-Keuls and Holm-Sidak methods, respectively. A two-tailed $p<0.05$ was considered significant.

\section{RESULTS}

Sixteen preterm infants were studied. Their birthweight (median and interquartile range) was 928 (812-1130) g and GA was 27.5 (25.5-30.0) wk. At the time of study, they were 10 (5-19) d old, 30 (29-31) wk postmenstrual age, and weighed 960 (870-1190) g. Of the 16 infants studied, 10 were male. Fifteen infants had been mechanically ventilated before the study, and 12 had received surfactant. Ten of them were on $0.21 \mathrm{FiO}_{2}$ and six required supplemental oxygen ranging from 0.23 to $0.30 \mathrm{FiO}_{2}$ at the time of study. All infants were receiving caffeine.

All 16 infants completed the five 1-h study periods, and there were no observed adverse events. Abdominal circumference did not change between study periods.

The mean $\mathrm{V}_{\mathrm{T}}$ obtained from all spontaneous breaths and ventilator cycles (NIMV or S-NIMV), RR and the resulting $\mathrm{V}_{\mathrm{E}}$ did not differ significantly between the NCPAP, NIMV, and S-NIMV periods. Measures of gas exchange including mean levels of $\mathrm{TcPCO}_{2}, \mathrm{SPO}_{2}$, and $\mathrm{FiO}_{2}$ did not differ between periods (Table 1).

Spontaneous inspiratory effort was reduced during S-NIMV compared with NCPAP and NIMV (Table 2). This was reflected in a reduction in per-breath $\mathrm{P}_{\mathrm{ES}}$ peak inspiratory during S-NIMV at 40/min compared with NCPAP and a reduction in per-breath $\mathrm{P}_{\mathrm{ES}}$ inspiratory area during S-NIMV at 40/min compared with all other study periods. Minute inspiratory effort evaluated by $\mathrm{P}_{\mathrm{ES}}$ minute inspiratory area was reduced during SNIMV at $20 / \mathrm{min}$ compared with NCPAP and NIMV at $20 / \mathrm{min}$. The reduction in $\mathrm{P}_{\mathrm{ES} \text { minute inspiratory area }}$ was more striking during S-NIMV at $40 / \mathrm{min}$. In contrast, inspiratory effort during NIMV did not differ from NCPAP.

The reduction in inspiratory effort during S-NIMV is illustrated in Figure 1. This representative recording during SNIMV at $40 /$ min shows reductions in $P_{E S}$ peak inspiratory and $\mathrm{P}_{\text {ES inspiratory area }}$ temporally associated with S-NIMV cycles 
Table 1. Ventilation and gas exchange

\begin{tabular}{|c|c|c|c|c|c|}
\hline & NCPAP & $\begin{array}{l}\text { NIMV at } \\
20 / \mathrm{min}\end{array}$ & $\begin{array}{l}\text { S-NIMV at } \\
20 / \mathrm{min}\end{array}$ & $\begin{array}{l}\text { NIMV at } \\
40 / \mathrm{min}\end{array}$ & $\begin{array}{l}\text { S-NIMV at } \\
40 / \mathrm{min}\end{array}$ \\
\hline $\mathrm{V}_{\mathrm{T}}(\mathrm{AU})$ & $10.6(8.0-13.9)$ & $11.6(7.8-19.6)$ & $10.2(7.8-14.6)$ & $10.4(6.2-14.1)$ & $10.1(8.7-13.5)$ \\
\hline Minute ventilation (AU/min) & $508(369-857)$ & $681(321-1051)$ & $535(342-783)$ & $546(330-746)$ & $581(399-811)$ \\
\hline RR (breaths/min) & $54(43-59)$ & $54(44-60)$ & $51(44-60)$ & $50(45-61)$ & $52(45-61)$ \\
\hline $\mathrm{TcPCO}_{2}(\mathrm{~mm} \mathrm{Hg})$ & $55.2 \pm 10.4$ & $55.1 \pm 10.7$ & $54.9 \pm 10.7$ & $56.3 \pm 11.1$ & $55.8 \pm 12.3$ \\
\hline $\mathrm{SpO}_{2}(\%)$ & $92.5 \pm 1.9$ & $92.9 \pm 2.6$ & $92.5 \pm 2.9$ & $92.9 \pm 2.7$ & $92.2 \pm 2.8$ \\
\hline $\mathrm{FiO}_{2}$ & $0.25 \pm 0.34$ & $0.25 \pm 0.44$ & $0.26 \pm 0.55$ & $0.25 \pm 0.41$ & $0.25 \pm 0.39$ \\
\hline
\end{tabular}

Data in median (inter-quartile range) or mean $\pm \mathrm{SD} . \mathrm{V}_{\mathrm{T}}$ is the mean $\mathrm{V}_{\mathrm{T}}$ from all spontaneous breaths and S-NIMV or NIMV cycles during each mode of support.

Table 2. Spontaneous inspiratory effort, active spontaneous expiratory effort, and chest wall distortion

\begin{tabular}{|c|c|c|c|c|c|}
\hline & NCPAP & $\begin{array}{l}\text { NIMV at } \\
20 / \mathrm{min}\end{array}$ & $\begin{array}{l}\text { S-NIMV at } \\
20 / \mathrm{min}\end{array}$ & $\begin{array}{l}\text { NIMV at } \\
40 / \mathrm{min}\end{array}$ & $\begin{array}{c}\text { S-NIMV at } \\
40 / \mathrm{min}\end{array}$ \\
\hline $\mathrm{P}_{\mathrm{ES} \text { peak inspiratory }}\left(\mathrm{cm} \mathrm{H}_{2} \mathrm{O}\right)$ & $6.1 \pm 2.7$ & $5.6 \pm 2.4$ & $5.5 \pm 2.8$ & $5.7 \pm 2.9$ & $4.8 \pm 2.6^{*}$ \\
\hline $\mathrm{P}_{\text {ES inspiratory area }}\left(\mathrm{cm} \mathrm{H}_{2} \mathrm{O} \cdot \mathrm{s}\right)$ & $2.1 \pm 0.8$ & $1.9 \pm 0.7$ & $1.9 \pm 0.9$ & $1.9 \pm 0.9$ & $1.7 \pm 0.8 \dagger$ \\
\hline $\mathrm{P}_{\mathrm{ES} \text { minute inspiratory area }}\left(\mathrm{cm} \mathrm{H}_{2} \mathrm{O} \cdot \mathrm{s} \cdot \mathrm{min}\right)$ & $114 \pm 61$ & $104 \pm 51$ & $99 \pm 59 \ddagger$ & $106 \pm 59$ & $93 \pm 58 \dagger$ \\
\hline $\mathrm{P}_{\text {ES peak expiratory }}\left(\mathrm{cm} \mathrm{H}_{2} \mathrm{O}\right)$ & $0.37 \pm 0.10$ & $0.47 \pm 0.14 \S$ & $0.45 \pm 0.22 \S$ & $0.46 \pm 0.13 \S$ & $0.36 \pm 0.12$ \\
\hline Phase angle $\left({ }^{\circ}\right)$ & $55 \pm 23$ & $51 \pm 27$ & $52 \pm 25$ & $50 \pm 24$ & $49 \pm 25$ \\
\hline TCD ratio & $1.96 \pm 1.61$ & $1.86 \pm 1.52$ & $1.64 \pm 0.72$ & $1.81 \pm 0.89$ & $1.51 \pm 0.44$ \\
\hline
\end{tabular}

Data in mean \pm SD.

$* p<0.05$ compared with NCPAP.

$\dagger p<0.05$ compared with all other periods.

$\ddagger p<0.05$ compared with NCPAP and NIMV at 20/min.

$\S p<0.05$ compared with NCPAP and S-NIMV at $40 / \mathrm{min}$
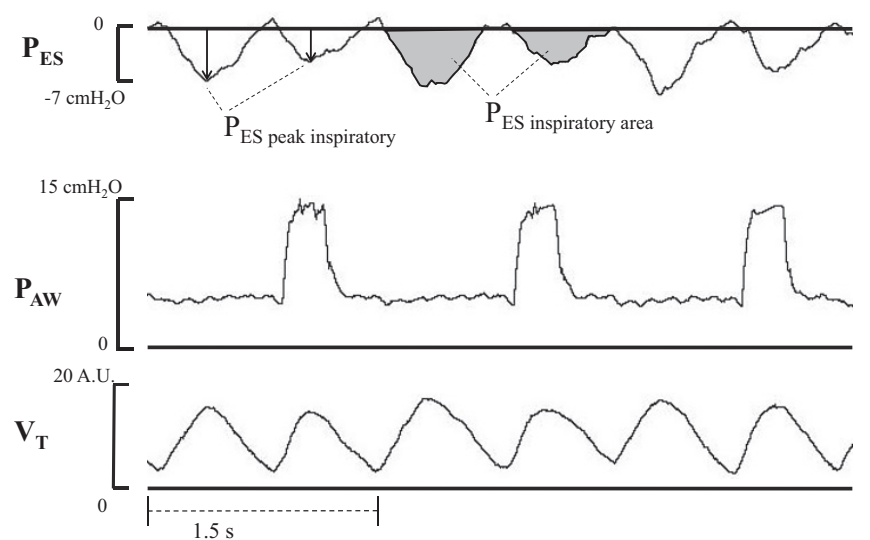

Figure 1. Representative recording during S-NIMV at 40/min. Tracings of $\mathrm{P}_{\mathrm{ES}}, \mathrm{P}_{\mathrm{AW}}$, and $\mathrm{V}_{\mathrm{T}}$ during S-NIMV at $40 / \mathrm{min}$ show reductions in inspiratory effort (smaller $\mathrm{P}_{\mathrm{ES}}$ peak inspiratory and $\mathrm{P}_{\mathrm{ES}}$ inspiratory area) temporally associated with S-NIMV cycles compared with nonassisted spontaneous breaths. $V_{T}$ during the S-NIMV cycles was decreased slightly.

compared with nonassisted spontaneous breaths. $\mathrm{V}_{\mathrm{T}}$ during the S-NIMV cycles also decreased slightly.

Active spontaneous expiratory effort evaluated by $\mathrm{P}_{\mathrm{ES} \text { peak }}$ expiratory increased during NIMV at 20, S-NIMV at 20/min, and NIMV at 40/min compared with NCPAP. In contrast, active exhalation pressure did not increase during S-NIMV at 40/min compared with NCPAP (Table 2). Chest wall distortion indices of phase shift angle and TCD ratio did not differ between NIMV, S-NIMV, and NCPAP (Table 2).

Analysis of the timing of ventilator cycle with respect to the spontaneous breath showed that 88 and $89 \%$ of ventilator cycles were delivered in synchrony (defined as delivered within the first half of spontaneous inspiration) during SNIMV at 20/min and $40 / \mathrm{min}$, respectively. This compared with only 21 and $23 \%$ of ventilator cycles during NIMV at 20/min and 40/min, respectively. Asynchrony was frequent during NIMV at 20/min and 40/min with $56 \%$ of ventilator cycles delivered during spontaneous exhalation. In contrast, only 5 and $6 \%$ of ventilator cycles were delivered during exhalation during S-NIMV at 20/min and 40/min, respectively. Although there were no significant differences in the mean $\mathrm{V}_{\mathrm{T}}$ from spontaneous and mechanical cycles obtained during each mode of support, there was considerable between patient variability. In half of the infants, $\mathrm{V}_{\mathrm{T}}$ from S-NIMV and NIMV cycles delivered during inspiration was larger than the $\mathrm{V}_{\mathrm{T}}$ from spontaneous breaths.

There were important effects related to the timing of ventilator cycle during NIMV at 20 and 40/min. This is shown in Table 3 for NIMV at 20/min (data during NIMV at $40 / \mathrm{min}$ is not shown to avoid redundancy). NIMV cycles delivered late in spontaneous inspiration (second half) and during the spontaneous exhalation prolonged the duration of exhalation and delayed the onset of the next spontaneous inspiration compared with spontaneous breaths during NCPAP and nonassisted spontaneous breaths during NIMV.

Only NIMV cycles delivered within the first half of spontaneous inspiration produced a decrease in per-breath spontaneous inspiratory effort as shown by a significantly lower $\mathrm{P}_{\mathrm{ES}}$ inspiratory area. As expected, this reduction was similar to that observed during cycles. $\mathrm{V}_{\mathrm{T}}$ obtained from spontaneous breaths during NCPAP, nonassisted spontaneous breaths between NIMV cycles, NIMV cycles delivered early or late in inspiration or during exhalation, nonassisted spontaneous breaths between S-NIMV cycles or between S-NIMV cycles did not differ significantly. However, there was considerable between-patient variability.

NIMV cycles delivered during exhalation produced an increase in expiratory effort to actively exhale against the ven- 
Table 3. Per-breath effects of the timing of ventilator cycles during NIMV and S-NIMV at 20 cycles per minute

\begin{tabular}{lcccccccc}
\hline & $\begin{array}{c}\text { Spontaneous } \\
\text { breaths during } \\
\text { NCPAP }\end{array}$ & $\begin{array}{c}\text { Spontaneous } \\
\text { breaths during } \\
\text { NIMV }\end{array}$ & $\begin{array}{c}\text { NIMV cycles } \\
\text { at early } \\
\text { inspiration }\end{array}$ & $\begin{array}{c}\text { NIMV cycles } \\
\text { at late } \\
\text { inspiration }\end{array}$ & $\begin{array}{c}\text { NIMV cycles } \\
\text { at early } \\
\text { expiration }\end{array}$ & $\begin{array}{c}\text { NIMV cycles } \\
\text { at late } \\
\text { expiration }\end{array}$ & $\begin{array}{c}\text { Spontaneous } \\
\text { breaths during } \\
\text { S-NIMV }\end{array}$ & $\begin{array}{c}\text { S-NIMV } \\
\text { cycles }\end{array}$ \\
\hline $\mathrm{V}_{\mathrm{T}}(\mathrm{AU})$ & $10.6(8.0-13.9)$ & $10.5(7.9-13.9)$ & $11.1(8.0-18.5)$ & $12.5(8.5-18.9)$ & $11.1(8.1-18.5)$ & $11.6(8.2-17.2)$ & $9.8(7.4-15.6)$ & $11.1(8.3-15.1)$ \\
Expiratory duration $(\mathrm{s})$ & $0.56 \pm 0.14$ & $0.56 \pm 0.13$ & $0.57 \pm 0.13$ & $0.66 \pm 0.20^{*}$ & $0.73 \pm 0.19 *$ & $0.69 \pm 0.13 *$ & $0.57 \pm 0.15$ & $0.60 \pm 0.15$ \\
$\mathrm{P}_{\mathrm{ES} \text { inspiratory area }}\left(\mathrm{cm} \mathrm{H}_{2} \mathrm{O} \cdot \mathrm{s}\right)$ & $2.1 \pm 0.8$ & $1.9 \pm 0.7$ & $1.6 \pm 0.6 \dagger$ & $1.8 \pm 0.7$ & $1.9 \pm 0.8$ & $2.0 \pm 0.7$ & $2.1 \pm 1.2$ & $1.6 \pm 1.0 \dagger$ \\
$\mathrm{P}_{\mathrm{ES} \text { peak expiratory }}\left(\mathrm{cm} \mathrm{H}_{2} \mathrm{O}\right)$ & $0.37 \pm 0.10$ & $0.40 \pm 0.14$ & $0.50 \pm 0.24$ & $0.53 \pm 0.38$ & $0.62 \pm 0.24 *$ & $0.99 \pm 0.38^{*}$ & $0.47 \pm 0.29$ & $0.48 \pm 0.24$ \\
\hline
\end{tabular}

Data in median (inter-quartile range) or mean \pm SD. NIMV cycles in early inspiration or expiration defined as delivered during the first half of inspiration or expiration. NIMV cycles in late inspiration or expiration defined as delivered after the second half of inspiration or expiration, respectively.

$* p<0.05 v s$ spontaneous breaths, NIMV cycles at early inspiration and S-NIMV cycles.

$\dagger p<0.05$ vs all other.

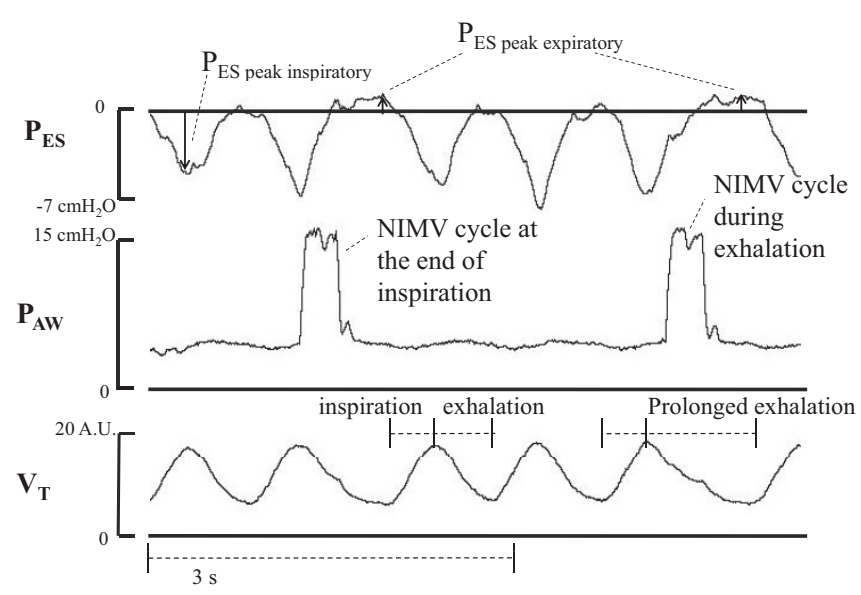

Figure 2. Representative recording during NIMV at 20 cycles per minute Recordings of $\mathrm{P}_{\mathrm{ES}}, \mathrm{P}_{\mathrm{AW}}$, and $\mathrm{V}_{\mathrm{T}}$ during nonsynchronized NIMV at $20 / \mathrm{min}$ showing increased positive pressure deflection in $\mathrm{P}_{\mathrm{ES}}$ during exhalation and prolongation of the expiratory phase with NIMV cycles delivered at the beginning of exhalation compared with nonassisted spontaneous breaths. The prolonged exhalation is evidenced by a slower decline in volume.

tilator, as reflected by a significantly greater $\mathrm{P}_{\mathrm{ES} \text { peak expiratory }}$ (Table 3). This is illustrated in Figure 2 with a representative tracing during NIMV at 20/min showing the positive deflection in $\mathrm{P}_{\mathrm{ES}}$ and a prolonged expiration with a slow decline in $\mathrm{V}_{\mathrm{T}}$ during NIMV cycles delivered in expiration.

Episodes with $\mathrm{SpO}_{2}<85 \%$ and percent of time spent with $\mathrm{SpO}_{2}<85 \%$ did not differ between study periods. Episodes of apnea or bradycardia were not observed. The patient comfort scale did not show differences between NCPAP, NIMV, and S-NIMV.

\section{DISCUSSION}

Contrary to the hypothesis, S-NIMV did not increase the mean $\mathrm{V}_{\mathrm{T}}$ and $\mathrm{V}_{\mathrm{E}}$ compared with NCPAP or NIMV in this group of clinically stable preterm infants. Nonetheless, synchronization produced a significant reduction in spontaneous breathing effort compared with NCPAP that was more striking at the higher S-NIMV rate. In contrast, there was no reduction in breathing effort during nonsynchronized NIMV.

The lack of effect of S-NIMV on ventilation and gas exchange may be because these infants were stable on NCPAP. With spontaneous ventilation and lung recruitment maintained adequately during NCPAP, they only reduced their effort in response to the assistance provided by S-
NIMV. Previous studies reported similar findings with synchronized nasal ventilation at similar cycling rates $(15,16)$. Conversely, Moretti et al. (17) reported increased $\mathrm{V}_{\mathrm{T}}$ and $\mathrm{V}_{\mathrm{E}}$ with S-NIMV compared with NCPAP immediately after extubation. This can be in part explained by the greater ventilatory demands during the transition to NCPAP and the use of a relatively low PEEP $\left(3 \mathrm{~cm} \mathrm{H}_{2} \mathrm{O}\right)$ in that trial.

The effect of NIMV or S-NIMV cycles on $\mathrm{V}_{\mathrm{T}}$ varied considerably between infants. Compared with the $V_{T}$ from spontaneous breaths, $\mathrm{V}_{\mathrm{T}}$ from S-NIMV cycles and NIMV cycles delivered during inspiration was greater in $50 \%$ of the infants. The factors that influence the increase in $V_{T}$ remain to be determined.

In this study synchronization during nasal ventilation reduced spontaneous breathing effort. However, this effect was not observed during NIMV. Further analysis revealed that only NIMV cycles delivered early in the spontaneous inspiration decreased spontaneous inspiratory effort. These findings suggest that synchronization during nasal ventilation successfully unloads the infant's respiratory pump.

It can be argued that the smaller negative deflection in $\mathrm{P}_{\mathrm{ES}}$ is because of the transmission of the positive pressure instead of a reduction in inspiratory effort. However, the magnitude of the pressure transmitted is smaller at lower GA because of the highly compliant chest wall (18). Thus, the pressure transmitted is likely smaller than the reduction in inspiratory pressure observed in this study during S-NIMV.

The lack of a consistent increase in ventilation was unexpected and did not fully agree with studies showing advantages of S-NIMV (with the same ventilator) compared with NCPAP immediately after extubation (6-9) or NIMV in infants with RDS $(10,11)$. However, a reduced inspiratory effort with S-NIMV could facilitate the maintenance of ventilation shortly after extubation when preterm infants have to compensate for the withdrawn ventilatory support. Khalaf $e t$ al. (8) showed that the benefits of S-NIMV after extubation were greater among infants with worse lung mechanics in whom the respiratory pump has to overcome increased mechanical loads to generate the required $\mathrm{V}_{\mathrm{T}}$. In contrast, the infants included in this study had already reached stability on NCPAP and did not need to overcome the challenges experienced by recently extubated infants.

The reduced inspiratory effort temporally associated with S-NIMV cycles was accompanied by a slightly reduced $\mathrm{V}_{\mathrm{T}}$, suggesting the S-NIMV cycles were sensed by the infant but 
the transmitted pressure was not sufficient to increase $\mathrm{V}_{\mathrm{T}}$. A similar effect was observed in NIMV cycles delivered during inspiration. However, NIMV cycles delivered in expiration prolonged the duration of expiration and often elicited an active effort to exhale.

The reduction in inspiratory breathing effort observed during S-NIMV cycles, also seen during NIMV cycles delivered in early inspiration, suggests that timely delivery of the positive pressure plays an important role in achieving respiratory unloading during nasal ventilation. The synchronous cycles did not increase $\mathrm{V}_{\mathrm{T}}$; therefore, it is unlikely that the decreased inspiratory effort was related to stretch receptor activity. The reduction in inspiratory effort may be mediated by a reflex activated by a jet of gas flow into the nasal passages (19).

Although adequate synchrony between the ventilator cycle and the spontaneous inspiration was achieved for the purposes of the study using the Graseby capsule, similar rates of synchrony may not be achieved during routine use and without the guidance of the $\mathrm{P}_{\mathrm{ES}}$ deflection during inspiration. Nonetheless, this method of synchronization was used in clinical trials that showed advantages of S-NIMV compared with NCPAP after extubation (6-8).

In this study, asynchrony during NIMV cycles delivered late in the spontaneous inspiration or during exhalation disrupted the infant's spontaneous breathing pattern. These elicited active expiratory efforts against the ventilator cycle, delayed the spontaneous exhalation, and consequently delayed the onset of the next inspiration. This disturbance of the infant's respiratory rhythm was likely mediated by pulmonary stretch receptor activity. Surprisingly, the better infantventilator interaction during S-NIMV did not improve gas exchange. However, the duration of each mode was relatively short, and the study has not captured important effects that may occur over longer periods.

Thoracoabdominal asynchrony is common in preterm infants, and synchronization can improve chest wall stability and reduce asynchrony $(16,20)$. In this study, there was minimal chest wall distortion during NCPAP perhaps reflecting the stability of the infants or their postconceptional age and S-NIMV or NIMV had minimal effects.

In this group of infants, the frequency of apnea and hypoxemia spells was minimal during NCPAP and did not change between study periods. Therefore, the advantages of NIMV or S-NIMV need to be evaluated in infants showing more frequent spells of apnea or hypoxemia during NCPAP than the population included in this study.

A previous study reported discomfort in preterm infants receiving NIMV and NCPAP compared with spontaneous breathing (21). In this study, there were no differences between NCPAP, NIMV, and S-NIMV in terms of the patient comfort scale. Increased risk of developing gastric and intestinal perforation with nasal ventilation has also been reported (22). In this study, there were no differences in abdominal girth between or during NCPAP, NIMV, and S-NIMV. However, because of the brief duration of each mode, these data cannot rule out the risk of gas being pushed in to the stomach during longer periods of nasal ventilation.
There were minimal differences on ventilation or gas exchange between ventilator rates of 20 and 40 cycles per minute with NIMV or S-NIMV. However, this group of stable preterm infants was likely more capable to compensate for the reduced support than sicker or less stable infants. Moreover, the finding of reduced breathing effort with S-NIMV at 40 versus $20 / \mathrm{min}$ should be interpreted with caution until longer term data show that higher S-NIMV rates do not increase the risk of adverse effects.

An important limitation of this study is that it documented only short-term effects of NIMV and S-NIMV. It cannot be excluded that there may be more striking effects of synchronization during longer periods of support. Although PIP was kept at $10 \mathrm{~cm} \mathrm{H}_{2} \mathrm{O}$ above PEEP during the study, it may have been insufficient because of the resistance of the upper airway or because variable gas leaks (e.g. opening of the mouth) can affect pressure transmission during nasal ventilation. A possible limitation of this study is the ability to detect small changes in $\mathrm{V}_{\mathrm{T}}$ by noninvasive measurements with RIP. However, Brooks et al. (23) showed a significant linear relationship between $\mathrm{V}_{\mathrm{T}}$ measured by pneumotachography and RIP over several hours, and this relationship was not affected by position, chest wall asynchrony, RR, or routine care.

In conclusion, ventilation and gas exchange did not improve during NIMV or S-NIMV compared with NCPAP and did not differ with synchronization in this group of clinically stable infants. Synchronized nasal ventilation reduced spontaneous breathing effort and prevented active exhalation. These effects were more striking at higher S-NIMV rates. Nasal ventilation without synchronization did not achieve a reduction in inspiratory effort and seemed to have no short-term advantages over NCPAP in relatively stable preterm infants. These findings cannot be extrapolated to sicker infants who could benefit more from nasal ventilatory support. The advantages of synchronization in such infants remain to be determined.

\section{REFERENCES}

1. Taghizadeh A, Reynolds ED 1976 Pathogenesis of bronchopulmonary dysplasia following hyaline membrane disease. Am J Pathol 82:241-264

2. Palta M, Gabbert D, Weinstein MR, Peters ME 1991 Multivariate assessment of traditional risk factors for chronic lung disease in very low birth weight neonates. J Pediatr 119:285-292

3. Davis PG, Henderson-Smart DJ 2003 Nasal continuous positive airways pressure immediately after extubation for preventing morbidity in preterm infants. Cochrane Database Syst Rev 2:CD000143

4. Ammari A, Suri M, Milisavljevic V, Sahni R, Bateman D, Sanocka U, RuzalShapiro C, Wung JT, Polin RA 2005 Variables associated with the early failure of nasal CPAP in very low birth weight infants. J Pediatr 147:341-347

5. Morley CJ, Davis PG, Doyle LW, Brion LP, Hascoet JM, Carlin JB 2008 Nasal CPAP or intubation at birth for very preterm infants. N Engl J Med 358:700-708

6. Friedlich P, Lecart C, Posen R, Ramicone E, Chan L, Ramanathan R 1999 A randomized trial of nasopharyngeal synchronized intermittent mandatory ventilation versus nasopharyngeal continuous positive airway pressure in very low birth weight infants after extubation. J Perinatol 19:413-418

7. Barrington KJ, Bull D, Finer NN 2001 Randomized trial of nasal synchronized intermittent mandatory ventilation compared with continuous positive airway pressure after extubation of very low birth weight infants. Pediatrics 107:638-641

8. Khalaf MN, Brodsky N, Hurley J, Bhandari V 2001 A prospective randomized, controlled trial comparing synchronized nasal intermittent positive pressure ventilation versus nasal continuous positive airway pressure as modes of extubation. Pediatrics 108:13-17

9. Moretti C, Giannini L, Fassi C, Gizzi C, Papoff P, Colarizi P 2008 Nasal fl ow-synchronized intermittent positive pressure ventilation to facilitate weaning in very low-birthweight infants: unmasked randomized controlled trial. Pediatr Int 50:85-91 
10. Bhandari V, Gavino RG, Nedrelow JH, Pallela P, Salvador A, Ehrenkranz RA, Brodsky NL 2007 A randomized controlled trial of synchronized nasal intermittent positive pressure ventilation in RDS. J Perinatol 27:697-703

11. Kugelman A, Feferkorn I, Riskin A, Chistyakov I, Kaufman B, Bader D 2007 Nasal intermittent mandatory ventilation versus nasal continuous positive airway pressure for respiratory distress syndrome: a randomized, controlled prospective study. J Pediatr 150:521-526

12. Sai Sunil Kishore M, Dutta S, Kumar P 2009 Early nasal intermittent positive pressure ventilation versus continuous positive airway pressure for respiratory distress syndrome. Acta Paediatr 98:1412-1415

13. Hummler H, Gerhardt T, Gonzalez A, Claure N, Everett R, Bancalari E 1996 Influence of different methods of synchronized mechanical ventilation on ventilation, gas exchange, patient effort, and blood pressure fluctuations in premature neonates. Pediatr Pulmonol 22:305-313

14. van Dijk M, Peters JW, van Deventer P, Tibboel D 2005 The COMFORT Behavior Scale: a tool for assessing pain and sedation in infants. Am J Nurs 105:33-36

15. Aghai ZH, Saslow JG, Nakhla T, Milcarek B, Hart J, Lawrysh-Plunkett R, Stahl G, Habib RH, Pyon KH 2006 Synchronized nasal intermittent positive pressure ventilation (SNIPPV) decreases work of breathing (WOB) in premature infants with respiratory distress syndrome (RDS) compared to nasal continuous positive airway pressure (NCPAP). Pediatr Pulmonol 41:875-881
16. Ali N, Claure N, Alegria X, D'Ugard C, Organero R, Bancalari E 2007 Effects of non-invasive pressure support ventilation (NI-PSV) on ventilation and respiratory effort in very low birth weight infants. Pediatr Pulmonol 42:704-710

17. Moretti C, Gizzi C, Papoff P, Lampariello S, Capoferri M, Calcagnini G, Bucci G 1999 Comparing the effects of nasal synchronized intermittent positive pressure ventilation (nSIPPV) and nasal continuous positive airway pressure (NCPAP) after extubation in very low birth weight infants. Early Hum Dev 56:167-177

18. Gerhardt T, Bancalari E 1980 Chest wall compliance in full-term and premature infants. Acta Paediatr Scand 69:359-364

19. Nonaka S, Katada A, Nakajima K, Ohsaki T, Unno T 1995 The effects of nasal flow stimulation on central respiratory pattern. Am J Rhinol 9:203-208

20. Kiciman NM, Andreasson B, Bernstein G, Mannino FL, Rich W, Henderson C, Heldt GP 1998 Thoracoabdominal motion in newborns during ventilation delivered by endotracheal tube or nasal prongs. Pediatr Pulmonol 25:175-181

21. Kugelman A, Bar A, Riskin A, Chistyakov I, Mor F, Bader D 2008 Nasal respiratory support in premature infants: short-term physiological effects and comfort assessment. Acta Paediatr 97:557-561

22. Garland JS, Nelson DB, Rice T, Neu J 1985 Increased risk of gastrointestinal perforations in neonates mechanically ventilated with either face mask or nasal prongs. Pediatrics 76:406-410

23. Brooks LJ, DiFiore JM, Martin RJ; The CHIME Study Group 1997 Assessment of tidal volume over time in preterm infants using respiratory inductance plethysmography. Pediatr Pulmonol 23:429-433 